\title{
Relation between plant water status and Macrosiphum euphorbiae (Hemiptera: Aphididae) population dynamics on three cultivars of tomato
}

\author{
Anna R. RIVELLI ${ }^{1}$, Vincenzo TROTTA², IRene TOMA² Paolo FANTI $^{2}$ and Donatella BATTAGLIA ${ }^{2 *}$ \\ ${ }^{1}$ School of Agricultural, Forestry, Food and Environmental Sciences, and ${ }^{2}$ Department of Sciences, University of Basilicata, \\ Viale dell’Ateneo Lucano 10, 85100 Potenza, Italy; e-mails: annarita.rivelli@unibas.it; vincenzo.trotta@unibas.it; \\ irene.toma@tiscali.it; paolo.fanti@unibas.it
}

Key words. Hemiptera, Aphididae, Macrosiphum euphorbiae, aphid population dynamics, Lycopersicon esculentum, water stress, trophic interaction

\begin{abstract}
Deficit irrigation scheduling is used to increase the efficiency with which water is used in many crops including tomato, however a water deficit is predicted to favour phloem feeding insects. We tested if and how different cultivars of tomato grown under water deficit conditions affect the population growth of the aphid Macrosiphum euphorbiae. Three tomato cultivars (Scintilla, Beefmaster and Rio Grande) were used in the experiments. The results for three watering regimes were compared with those of a control, which was well watered every three days: stressed plants received one third of the water supplied to the control over each three-day interval (experiment 1); stressed plants received a gradually decreasing amount of water (100\% at the first watering and then $80 \%, 60 \%, 50 \%, 40 \%$ and $20 \%$ ) every three days (experiment 2); stressed plants received the same amount of water as the control but at longer intervals, that is when evident signs of wilting appeared (experiment 3 ). The results showed that water stress either enhanced, had an adverse effect or had no effect on aphid population growth, depending on the cultivar and watering regime. No difference was recorded in the population dynamics of $M$. euphorbiae feeding on Beefmaster tomato plants subjected to different levels of water stress. In the case of the cultivar Scintilla, live aphids were less abundant on stressed plants than on well watered ones in experiment 1 and 3 but not in experiment 2 . The highest variability in aphid population dynamics on the plants grown under the different water stress protocols was recorded on the cultivar Rio Grande. In experiment 1, the initial peak in aphid numbers was higher on the water stressed plants than on the control and then decreased to lower numbers than on the control. In experiment 2 , there were no differences in the numbers of aphids infesting stressed and control plants. In experiment 3, there were fewer aphids on stressed than on control plants after six days, as in experiment 1 , but there was no initial peak in aphid numbers.
\end{abstract}

\section{INTRODUCTION}

There are two hypotheses that address the effect of host plant stress on arthropod pest populations: the "plant stress" hypothesis (White, 1969) and the "plant vigour" hypothesis (Price, 1991). The plant stress hypothesis, based on empirical data on pest outbreaks during drought periods, predicts that stressed plants are better hosts for herbivores (White, 1984; Mattson \& Haack, 1987). The plant vigour hypothesis, in contrast, predicts that phytophagous arthropods will prefer and perform better on rapidly growing plants and, consequently, less well when the plants are subject to stress. The plant vigour hypothesis (Price, 1991) is mainly based on experimental studies showing that imposed water stress conditions often negatively affect herbivore performance, either in terms of reduced population growth (Pons \& Tatchell, 1995; McVean \& Dixon, 2001), reduced fecundity and reproduction (Kennedy et al., 1958; Wearing \& van Emden, 1967; Wearing, 1972; Sumner et al., 1983; Inbar et al., 2001) or survival (Sumner et al., 1983; Watt, 1986). Most of these references relate to work with aphids, and in particular with different species of aphid, feeding on different host plants, and experiencing a variety of water stress treatments. In some cases the level of stress is kept constant by means of polyethylene glycol used as a medium for growing plants (Sumner et al., 1983), in other cases the maximum level of stress is kept constant by varying the water supply (Fereres et al., 1988). Sometimes the level of stress experienced by plants is not measured (Kennedy et al., 1958; Wearing, 1967; Wearing \& van Emden, 1967) or an indirect measure is provided (McVean \& Dixon, 2001). The main negative effect of water stress on the aphids is recorded in terms of the reduction in their reproductive capacity (Fereres et al., 1988; Pons \& Tatchell, 1995) and sometimes in terms of their "restless" behaviour (Kennedy et al., 1958; Miles et al., 1982). Nevertheless, the response to stress is not the same for all species of aphid and is affected by feeding site (Wearing, 1967; Wearing \& Van Emden, 1967).

Arthropod pests infesting plants experiencing water stress may simultaneously experience both favourable and detrimental conditions. In fact, during water stress, proteins can be hydrolyzed and plants may produce and accumulate nitrogen-containing osmoprotectants, resulting in increased levels of free amino acids (Brodbeck \& Strong, 1987), but turgor pressure and water content decrease (Hsiao, 1973, Inbar et al., 2001) and levels of allelochemicals may occasionally increase (Gershenzon, 1984; Mattson \& Haack, 1987; Inbar et al., 2001).

\footnotetext{
* Corresponding author; e-mail: donatella.battaglia@unibas.it
} 
Larsson (1989) suggests that physiological responses of plants to water deficit produce quite different consequences for specific feeding guilds of herbivorous insects. Since allelochemicals are less concentrated in vascular than leaf tissue (Raven, 1983), phloem feeders are predicted to show a stronger positive response to plant stress than chewing insects (Larsson, 1989). Nevertheless, the reduction in turgor pressure may compromise the potential benefits of elevated nitrogen and low allelochemical concentration for phloem feeding insects. Finally, the effect of concurrent favourable and detrimental factors may be in any case difficult to forecast. In the case of aphids (Aphididae), for example, drought stress enhances insect performance in some cases, increasing reproduction rate (Wearing, 1967), or speeding nymphal development (Miles et al., 1982), or promoting outbreaks in the field (Li et al., 2008). Nevertheless, in some other cases, all relating to aphids, drought stress has a detrimental (Miles et al., 1982; Sumner et al., 1986; Pons \& Tatchell, 1995; McVean \& Dixon, 2001) or little effect (McMurtry, 1962; Salas \& Corcuera, 1991).

Huberty \& Denno (2004), reviewing the literature on plant water stress and its consequences for herbivorous insects, proposed the "pulsed stress hypothesis", which suggests that phloem-feeding insects, like aphids, are expected to respond positively to intermittently stressed plants, where the recovery of turgor allows sap-feeders to benefit from increases in plant nitrogen induced by the stress, but are expected to perform poorly on continuously stressed plants. Huberty \& Denno (2004) in their meta-analysis of published studies, categorized stress treatments as intermittent if the experimental protocol involved sporadic watering of plants throughout the study, or continuous if plants were never watered after the start of the experiment.

The results presented in most of the literature on the performance of aphids on continuously stressed plants support the "pulsed stess" hypothesis (Kennedy et al., 1958; Sumner et al., 1986; McVean \& Dixon, 2001), but the situation seems to be much more complex in the case of intermittent stress. Variation in aphid reproductive fitness on intermittently stressed plants is strongly dependent on the species of aphid, even when infesting the same species of host plant (Wearing, 1967; Wearing \& Van Emden, 1967).

The pulsed stress hypothesis is particularly relevant as intermittent water stress is common in the field. The irrigation technique and watering schedule adopted may sometimes favour bouts of stress and, at the same time, shape stress dynamics. However, little is known about how stress dynamics affect insect performance. Moreover, cultivar specific features may be involved in the response to pulsed water stress. There are a few studies of insect dynamics on different host cultivars under drought stress but only for continuously water stressed plants (Sumner et al., 1986).

Tomato is an economically valuable crop grown both under field and greenhouse conditions. Most of the areas where tomatoes are produced are located in hot and dry climates (i.e. Mediterranean) where water stress is rather frequent. Moreover, deficit irrigation techniques, characterized by a reduced restoration of crop maximum evapotranspiration, may be applied to tomato crops in order to increase water use efficiency (Perniola et al., 1994). Physiological responses of tomato to drought stress largely depend on the characteristics of the cultivar, as net photosynthetic rate, stomatal conductance, transpiration rate and osmotic adjustment may differ significantly under the same water deficit conditions (Srinivasa Rao et al., 2001). Different tomato genotypes also display different levels of resistance to pests and diseases (Scott et al., 1995, 2001; Goggin et al., 2001; Cooper \& Goggin, 2005).

The effects of water stress (Aloni \& Pressman, 1981; Van Ieperen et al., 2003) and aphid infestation (Walgenbach, 1997) on the growth, development and yield of tomato are fairly well known, while information on the interaction between these effects, e.g. which stresses are combined with each other, is limited. This study aimed to test the role of host plant cultivar in determining the aphid-plant relationship when the host plant is subjected to pulsed water stress. As a model, we chose the aphid Macrosiphum euphorbiae (Hemiptera: Aphididae), a worldwide pest of tomato of economic importance in terms of both direct damage (Houser et al., 1917; Walgenbach, 1997) and virus transmission (Braithwaite \& Blake, 1961; Chowfla et al., 1999).

In this paper we report the effects of pulsed water stress on the population growth of $M$. euphorbiae feeding on three cultivars of tomato (Lycopersicon esculentum Mill.).

\section{MATERIAL AND METHODS}

\section{Insects and plants}

Three cultivars of tomato were used in our experiments: Scintilla (cherry tomato, F1 hybrid), Beefmaster (beefsteak tomato, F1 hybrid) and Rio Grande (pear-shaped processing tomato for paste and concentrated juice). We bought tomato plants in polystyrene trays from a nursery that used seeds produced by OLTER. Seedlings were transplanted and grown individually in plastic pots (18 cm diameter, $19 \mathrm{~cm}$ height) holding $800 \mathrm{~g}$ of commercial soil (COMPO SANA ${ }^{\circledR}$ Universal Potting Soil).

A colony of Macrosiphum euphorbiae, obtained from the "Istituto per la Protezione delle Piante CNR, Portici", was reared in the laboratory on plants of the three tomato cultivars mentioned above for at least five generations ( 3 months) before being used in the experiments.

\section{Water stress experiments}

The experiment was carried out at the University of Basilicata, Italy $\left(40^{\circ} 36^{\prime} \mathrm{N}, 15^{\circ} 48^{\prime} \mathrm{E}\right)$ in a naturally lit and temperature-controlled glasshouse maintained at $26^{\circ} \mathrm{C}$ during the day and $18^{\circ} \mathrm{C}$ at night. Ten days after transplanting, when plants were almost $20 \mathrm{~cm}$ high and close to flowering, three apterous adults of $M$. euphorbiae were placed on plants of each of the three cultivars. The different water regimes for control and stressed plants were initiated just after the day of infestation, which was day 0 of the water treatments.

There were three experiments, each with a different way of inducing water stress and each in a completely randomized 
design. Control plants were well-watered, receiving $750 \mathrm{ml}$ of water per pot every three days.

In experiment 1, stressed plants were watered at the same time as the control, but received only one third of the water supplied to the control or, in experiment 2, a gradually decreasing water supply ( $100 \%$ at the first watering, and, afterwards, $80 \%$, $60 \%, 50 \%, 40 \%$ and $20 \%$ of the water supplied to the control). In both experiments, six plants per cultivar (a total of 18 plants) were water stressed and six plants per cultivar were used as a control (a total of 18 plants). The same watering regimes (control or stress) were applied to the other $6+6$ plants without aphids.

Experiment 3 was carried out simultaneously with experiment 2. Twelve other plants of cultivar Scintilla and six of cultivar Rio Grande were infested and watered only when they showed evident symptoms of wilting. Only two cultivars were used in experiment 3 because in experiment 1 the aphids infesting Beefmaster were apparently not affected by the different water stress levels experienced by their host.

Before watering, total leaf water potential $(\psi)$ was measured between 12:00 and 14:00 $\mathrm{h}$, on four to six plants per cultivar and treatment, always using the youngest top leaf, fully expanded and exposed to high light intensity (that is, with a Photosynthetically Active Radiation, PAR $>1200 \mu \mathrm{mol} \mathrm{m}{ }^{-2} \mathrm{~s}^{-1}$ ), using a Schlolander pressure chamber (PMS Instruments, Corvallis, OR, USA).

In each experiment, live aphids were counted every three days and any dead aphids trapped by plant trichomes were also counted and removed. The observations ended when no more aphids were found on plants.

\section{Statistical analysis}

The effects of "cultivar" (i.e., Scintilla, Beefmaster and Rio Grande), "day" and "stress" (i.e., the different watering regimes on control and test plants) on the number of live and dead aphids were appraised using an ANOVA for repeated measures (SYSTAT, version 12) (Systat, 2007).

Leaf water potential values were analyzed using a full factorial model analysis of variance (ANOVA), including the presence of aphids in addition to "cultivar", "day" and "stress" as main fixed effects.

\section{RESULTS}

\section{Experiment 1: Two third reduction in water supply}

Values of leaf water potential and number of live aphids are shown in Fig. 1. Number of dead aphids recorded trapped by plant trichomes are shown in Fig. 2. Water potential values were not affected by aphid infestation, but significantly differed with water stress in all the three cultivars (Fig. 1A) (Scintilla: $\mathrm{F}=516.49$; d.f. $=$ 1,28; $P<0.001$; Beefmaster: $\mathrm{F}=473.71$; d.f. $=1,28 ; P<$ $0.001 ; \mathrm{F}=19.24 ;$ d.f. $=1,29 ; P<0.001)$. The number of live aphids (Fig. 1B, C, D) differed significantly on the three cultivars $(\mathrm{F}=28.08$; d.f. $=2,30 ; \mathrm{P}<0.001)$, but were not associated with water stress $(\mathrm{F}=0.85$; d.f. $=$ $1,30 ; \mathrm{P}=0.36)$. The interaction cultivar $\times$ stress was significant $(\mathrm{F}=4.36$; d.f. $=2,30 ; \mathrm{P}=0.022)$, that is on cultivar Rio Grande the aphid population showed a higher initial peak on water stressed plants than on the other two cultivars tested and then decreased to lower numbers than on the control. For the same cultivar, water leaf water potential was lower than for the control and remained close to $-0.8 \mathrm{MPa}$, while water stressed plants of the cul-

\section{Experiment 1}
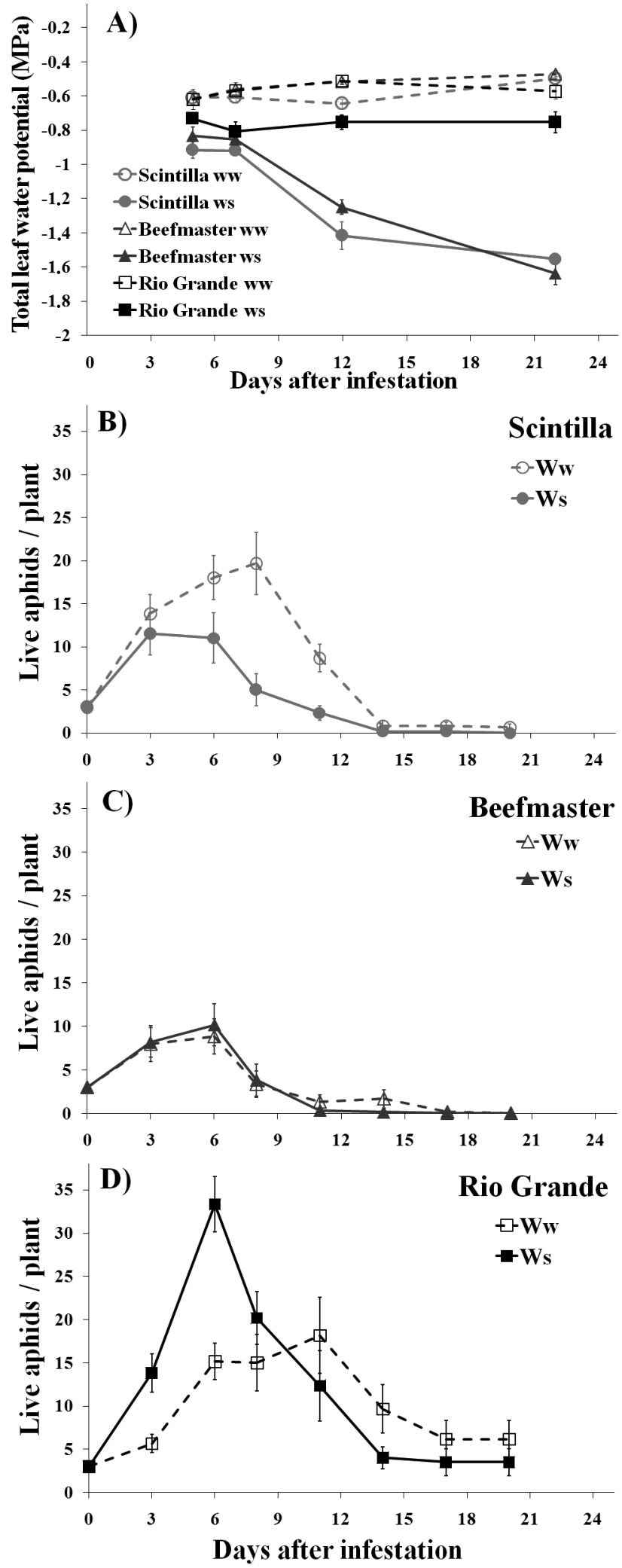

Fig. 1. The relationships recorded in experiment 1 (two third reduction in water supply) between the values (mean \pm s.e.) of leaf water potential $(\mathrm{A})$ and number $(\mathrm{mean} \pm$ s.e.) of live aphids/plant in the cultivars Scintilla (B), Beefmaster (C) and Rio Grande (D) from the day on which the plants were infested with aphids for a period of 34 days. In each treatment $n=6$; $\mathrm{Ww}=$ well watered plants; $\mathrm{Ws}=$ water stressed plants. 


\section{Experiment 1}
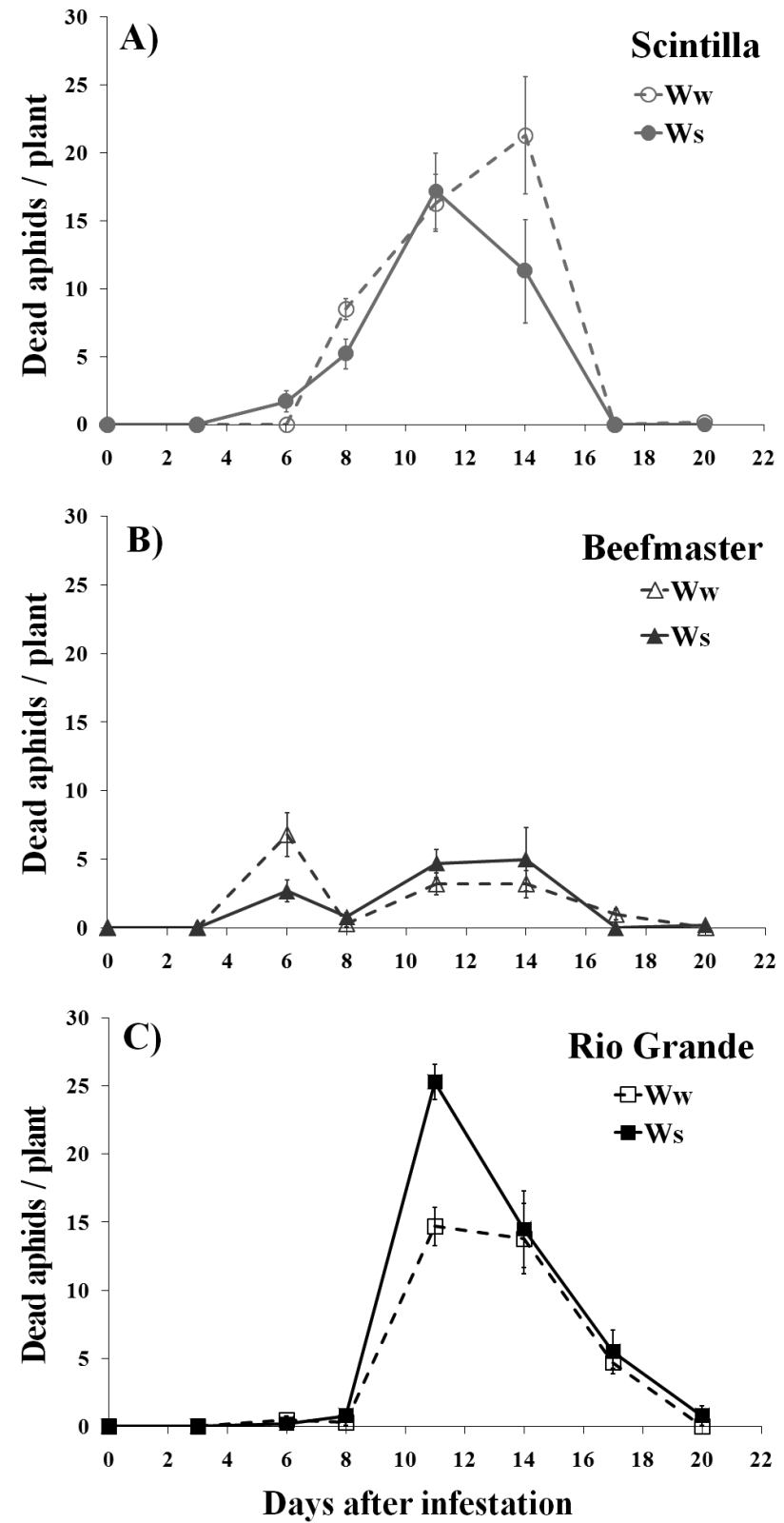

Fig. 2. The relationships recorded in experiment 1 (two third reduction water supply) between the number (mean \pm s.e.) of dead aphids trapped by leaf trichomes/plant on well watered and water stressed plants of the cultivars Scintilla (A), Beefmaster (B) and Rio Grande (C). In each treatment $\mathrm{n}=6$; $\mathrm{Ww}=$ well watered plants; $\mathrm{Ws}=$ water stressed plants.

tivars Scintilla and Beefmaster showed a sharp decrease in leaf water potential after the first week, reaching values of about $-1.6 \mathrm{MPa}$. On the cultivar Scintilla live aphids were less abundant on stressed plants than on well watered ones. No difference in aphid population dynamics was recorded on the cultivar Beefmaster. Numbers of dead aphids (Fig. 2) only differed among plant cultivars $(\mathrm{F}=16.32$; d.f. $=2,30 ; \mathrm{P}<0.001)$ and no significant difference was found associated with water stress $(\mathrm{F}=0.006 ;$ d.f. $=1,30 ; \mathrm{P}=0.94)$ or in the cultivar $\times$ stress interaction $(\mathrm{F}=2.52 ;$ d.f. $=2,30 ; \mathrm{P}=0.097)$. We

\section{Experiment 2}
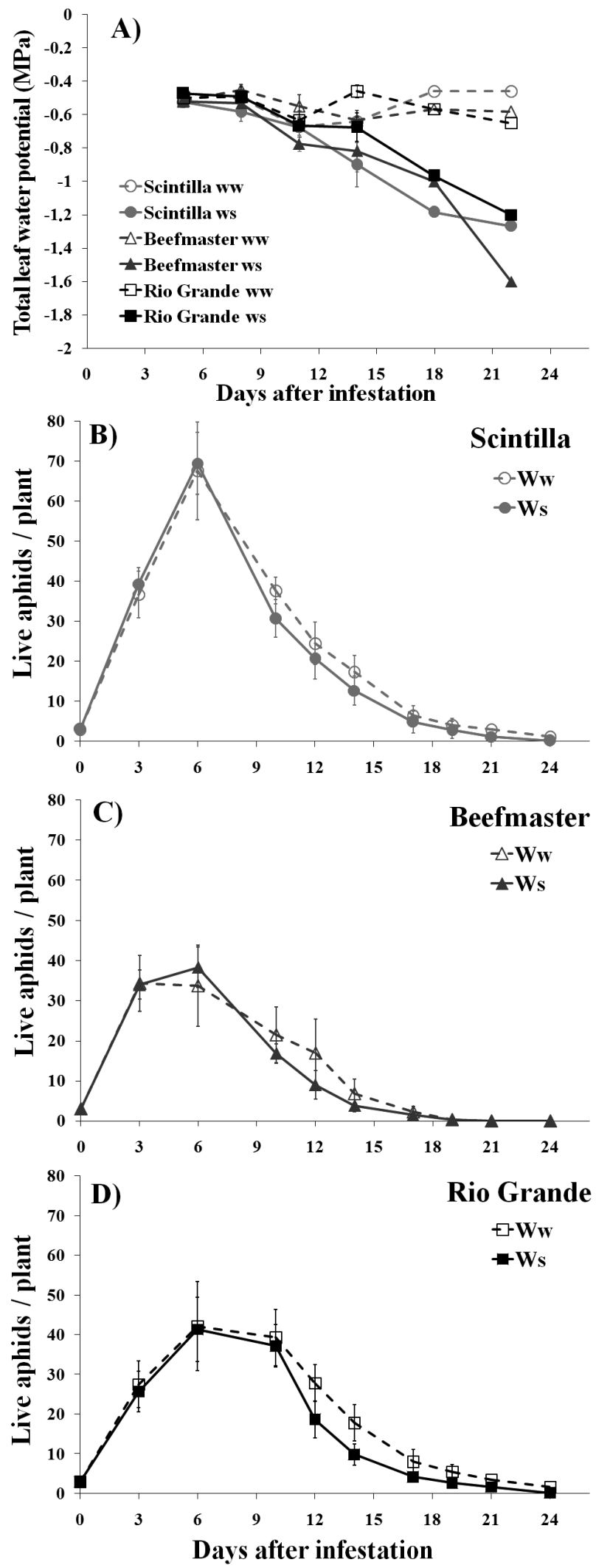

Fig. 3. The relationships recorded in experiment 2 (gradually decreasing water supply) between the values (mean \pm se) of leaf water potential (A) and number (mean $\pm \mathrm{se}$ ) of live aphids/plant recorded in the cultivars Scintilla (B), Beefmaster (C) and Rio Grande (D) from the day on which the plants were infested with aphids for a period of 34 days. In each treatment $\mathrm{n}=6 ; \mathrm{Ww}=$ well watered plants; Ws $=$ water stressed plants. 


\section{Experiment 2}
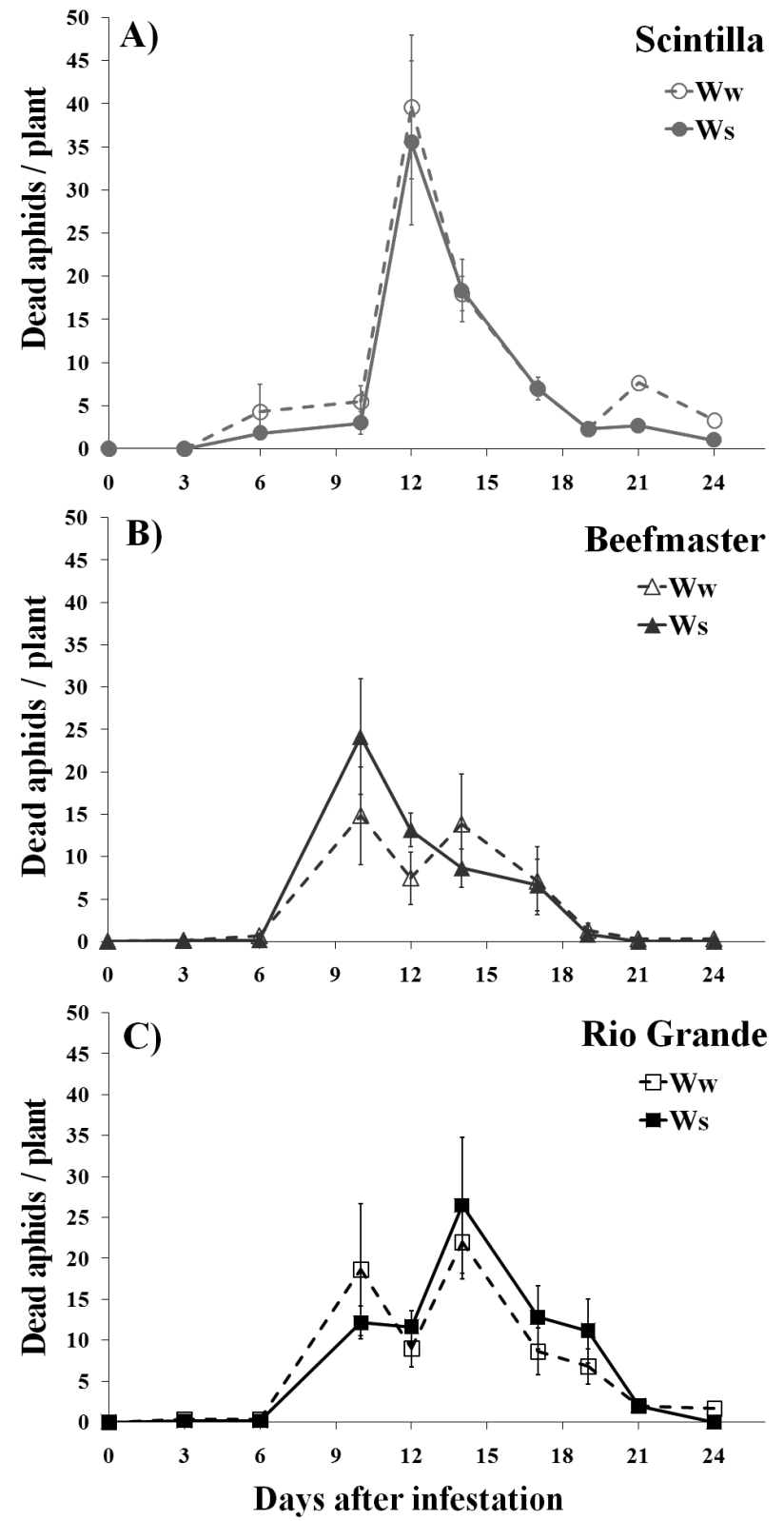

Fig. 4. The relationships recorded in experiment 2 (gradually decreasing water supply) between the number (mean \pm s.e.) of dead aphids trapped by leaf trichomes/plant on well watered and water stressed plants of cultivars Scintilla (A), Beefmaster (B) and Rio Grande (C). In each treatment $\mathrm{n}=6 ; \mathrm{Ww}=$ well watered plants; $\mathrm{Ws}=$ water stressed plants.

did not observe any change in the behaviour of the aphids on the three cultivars caused by water stress.

\section{Experiment 2: Gradually decreasing water supply}

Leaf water potential values and the number of live aphids are shown in Fig. 3.

Plant water potential values (Fig. 3A) of water stressed plants differed significantly from those of the control $(\mathrm{F}=$ 136.51 ; d.f. $=1,132 ; P<0.001)$ and there was no significant association with cultivar $(\mathrm{F}=1.91$; d.f. $=2,132 ;$ n.s. $)$ or the presence of aphids $(\mathrm{F}=0.15$; d.f. $=1,132$; n.s. $)$. Water potential gradually decreased in all three cultivars

\section{Experiment 3}
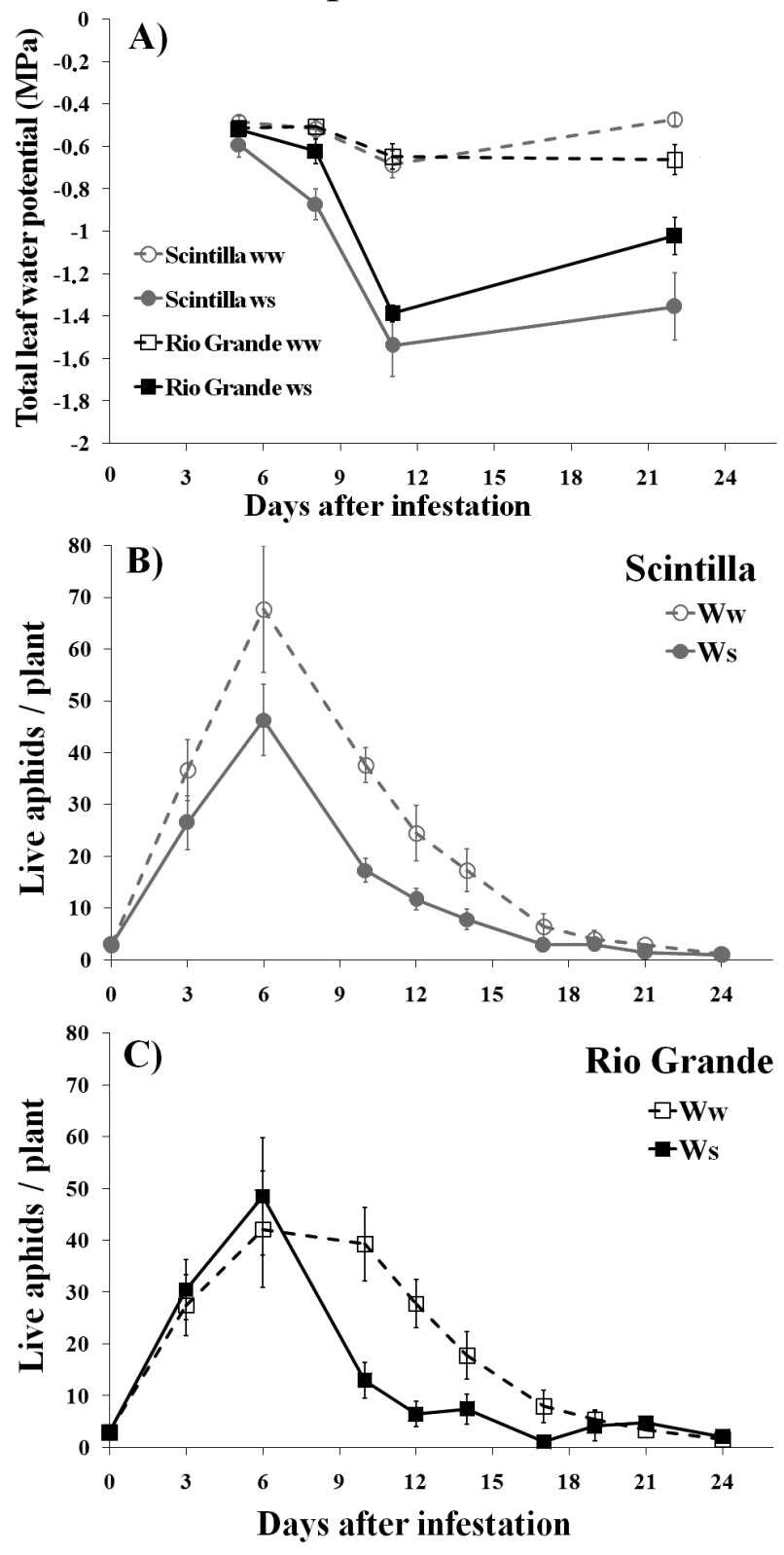

Fig. 5. The relationships recorded in experiment 3 (severe water stress) between the values (mean \pm s.e.) of leaf water potential (A) and number (mean \pm s.e.) of live aphids/plant recorded in the the cultivars Scintilla (B) and Rio Grande (C) from the day on which the plants were infested with aphids for a period of 34 days. In each treatment $n=6$ for cv. Rio Grande and $\mathrm{n}=12$ for cv. Scintilla; $\mathrm{Ww}=$ well watered plants; $\mathrm{Ws}=$ water stressed plants.

when water stressed but in this experiment the decrease was lower (but not statistically significantly so) in the cv. Rio Grande. The gradually decreasing water supply in experiment 2 resulted in no effect of plant water stress on aphid population dynamics (Fig. 2B, C, D) regardless of cultivar. In fact, aphid population dynamics was not affected by water stress $(\mathrm{F}=0.79$; d.f. $=1,30$; n.s. $)$ or by cultivar $(\mathrm{F}=0.55$; d.f. $=2,30$; n.s. $)$ and the interaction "stress $\times$ cultivar" was not significant $(F=0.27$; d.f. $=$ 


\section{Experiment 3}
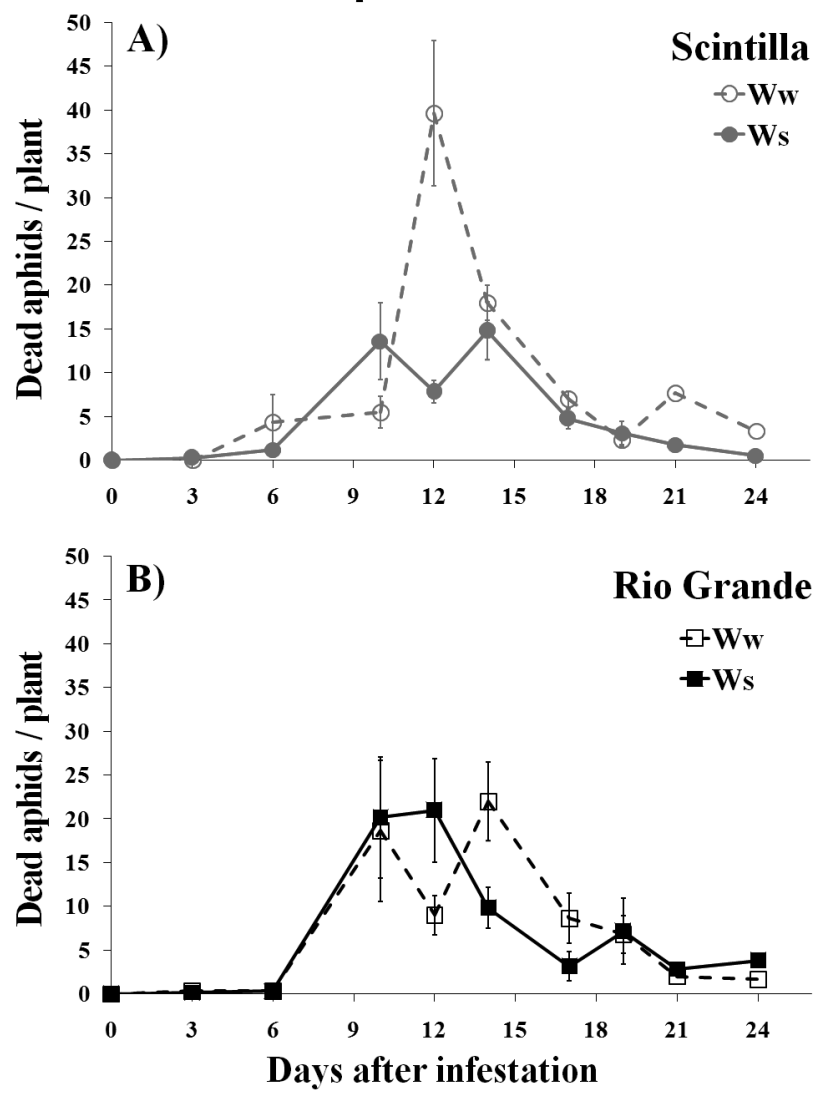

Fig. 6. The relationships recorded in experiment 3 (severe water stress) between the number (mean \pm s.e.) of dead aphids trapped by leaf trichomes/plant on well watered and water stressed plants of cultivars Scintilla (A) and Rio Grande (B). In each treatment $\mathrm{n}=6$ for $\mathrm{cv}$. Rio Grande and $\mathrm{n}=12$ for $\mathrm{cv}$. Scintilla; $\mathrm{Ww}=$ well watered plants; $\mathrm{Ws}=$ water stressed plants.

2,$30 ;$ n.s.). Similarly, there was no effect of water stress or cv on the number of dead aphids (Fig. 4).

\section{Experiment 3: Severe water stress}

In experiment 3 , stressed plants were watered only when they wilted.

Leaf water potential values (Fig. 5A) of water stressed plants differed significantly from those of the control $(\mathrm{F}=$ 116.90 ; d.f. $=1,55 ; P<0.001)$ and after the first week showed a sharper decrease than in the other two experiments. Also in this experiment the decrease was lower for cv. Rio Grande

The numbers of live aphids (Fig. 5B, C) on water stressed and control plants differed significantly $(\mathrm{F}=$ 11.31 ; d.f. $=1,26 ; \mathrm{P}=0.002)$ but the difference between their numbers on the three cultivars was not significant. Water stress had a detrimental effect on the numbers of live aphids. There were always fewer live aphids on stressed plants of Scintilla than on the controls. In the case of Rio Grande there were fewer live aphids on stressed plants than on the control after the sixth day, as in experiment 1 , but without the initial peak.

Numbers of dead aphids (Fig. 6) didn't differ significantly with stress and cultivar.

\section{DISCUSSION AND CONCLUSION}

This study was conducted in order to evaluate the effect of pulsed water stress on the population dynamics of $M$. euphorbiae on different genotypes of its tomato host. We recorded two parameters that describe aphid dynamics: variation in the numbers of live aphids over time and persistence of an aphid colony on a plant. In fact, among phloem-feeding insects, aphids have some peculiar features. Aphids have traits characteristic of r-strategist (Horn, 1976; Matthews \& Matthews, 1978; Matthews \& Kitching, 1984): a high reproductive potential and an unstable relationship with the host plant over time (Dixon, 1992; Dixon et al., 1993). After adult females settle on a new host plant, the aphid colony usually grows rapidly. When favourable conditions persist (low aphid density; high host quality) they continue to maximize investment in reproduction (Powell et al., 2006), afterwards, aphid density decreases as a consequence of crowding and/or declining plant quality (Mueller et al., 2001). When studying the effect of host plant features on aphid population dynamics, we therefore considered separately the rate at which aphid numbers increased and the persistence of the colony on the plant over time (McVean \& Dixon, 2001). Both parameters may dramatically change depending on the traits of the host plant (Larocca et al., 2011). In addition, we recorded the numbers of dead aphids stuck on leaf trichomes. In the case of Aphis fabae on broad bean and Brevicoryne brassicae on rape, aphids become restless on water stressed plants (Kennedy et al., 1958; Miles et al., 1982). It is reasonable to believe that this "restless" behaviour on stressed tomato plants would result in an increase in the numbers of aphids trapped by glandular trichomes and therefore an increase in mortality. We tested the hypotheses that water stress affects the numbers of live aphids, colony persistence and numbers of aphids trapped by trichomes on the three cultivars of tomato studied. We found that, among the parameters considered, "number of live aphids" was the only one affected by water stress whereas "colony persistence" and "number of aphids trapped by the trichomes" were independent of water stress. Our observations show that the manner in which water deficit is applied may differentially affect aphid population dynamics on different cultivars. In fact, no difference was observed in the population dynamics of $M$. euphorbiae feeding on Beefmaster tomato plants both under good or stressed conditions, whereas the increases in aphid numbers on Scintilla and Rio Grande stressed plants differed from that on the controls depending on water supply protocols. In particular, cultivar Rio Grande, a processing tomato, which is much more susceptible than the other two cultivars to aphids damage (Rivelli et al., 2012), is interesting in that aphid population dynamics on this cultivar were very variable and a function of the stress protocol.

That there is a relation between leaf water potential and aphid longevity and fecundity is reported by Sumner et al. (1983) for Schizaphis graminum feeding on Triticum aestivum. In this case, different levels of leaf water potential were determined by different concentrations of a polyeth- 
ylene glycol medium used for rearing plants. In this way moisture stress was precisely controlled and remained constant. Under these conditions of reduced turgor pressure it is difficult for aphids to feed. When water stressed plants are rewatered, as in our experiments, leaf turgor increases. Water potential, measured before watering, measures the minimum level of leaf water potential, which actually varies in the interval between two watering events. In this study, measures of leaf water potential are used as descriptive parameters, although not exhaustive, of plant stress during the course of the experiment. We recorded higher values of water potential for cultivar Rio Grande than the other two cultivars under the same water deficit conditions. The different response of Rio Grande need to be further addressed specifically in terms of plant physiology. Moreover, the Rio Grande response to water deficit depended on the stress treatment used. All this may have affected the aphids' reproductive performance on this cultivar.

In our experiments, the water regimes for control and stressed plants were initiated just after the plants were infested with aphids. Plant acclimation to stress is a dynamic process and includes osmotic adjustment (PérezAlfocea et al., 2006). The most striking change in the sieve tubes is the accumulation of amino acids, mainly free proline, which is induced by a particular threshold level of stress. This threshold may occur at water potentials that are not very negative. In alfalfa, for example, accumulation of proline occurs below a threshold value of about -0.9 MPa (Cirousse et al., 1996). To transfer aphids to plants just before they were stressed and not when they were stressed enabled us to observe the aphid colony during the whole dynamic process occurring in the host plant, in a way similar to that reported by McVean \& Dixon (2001). Applying the water treatments before infesting the plants with aphids would have addressed different questions, including the acceptability of the host plant for $M$. euphorbiae.

McVean \& Dixon (2001) tested the hypotheses that the numbers of aphid decline at a younger plant growth stage on drought-stressed plants, but in the case of Acyrthosiphon pisum on pea plants, they found that the persistence of the colony on the host plant is independent of drought stress. Our data for M. euphorbiae on tomato confirm this result. Factors other than stress and cultivar determined the persistence of $M$. euphorbiae colonies on plants. In our experiments, aphids disappeared from plants about twenty days after the beginning of the infestation. This is a short time compared with colony persistence reported for other aphid species on different host plants (McVean \& Dixon, 2001; Larocca et al., 2011). Results of other studies in glasshouse and open field conditions (Battaglia et al., unpubl. results), seem to support the idea that the short persistence of colonies of $M$. euphorbiae on tomato plants is related to their phenological development in terms of flowering. Colony decline could be caused by the induction of host plant defences against insects and/or by a reduction in the availability of nitrogen at this particular phenological stage. It is known that plant ontogeny affects resource allocation and can constrain the expression of resistance to damage by herbivores (Boege \& Marquis, 2005). In any case, the disappearance of the aphid colonies in our experiments did not seem to be due to overpopulation or host plant deterioration/collapse. Stressed plants only showed slight symptoms of senescence in terms of the yellowing of basal leaves.

The decline in the number of live aphids might have been due to alatae production, but we have no reliable data supporting this hypothesis, because we didn't check the proportion of 4th instar nymphs with developing wing pads and adult alatae were free to leave the plants. Poor nutritional quality of host plant has long been implicated in the production of winged morphs (Wadley, 1923; Bonnemaison, 1951; Mittler \& Dadd, 1966; Dixon \& Glen, 1971), though there is no clear pattern in the effect of nutrition on wing induction (Müller et al., 2001). Also, in the case of water stress, there is no clear evidence that this stress affects the production of winged morphs (Baugh \& Phillips, 1991; Pons \& Tatchell, 1995; McVean \& Dixon, 2001). It is noteworthy that the rapid decline in the numbers of aphids on water stressed Rio Grande plants after day 6 in experiment 1 , cannot be explained just in terms of higher aphid mortality. In fact, on day 8 the number of live aphids was already declining but that of dead aphids was still very low. Moreover, any contribution alatae dispersal made to the reduction in numbers of aphids on stressed plants only served to magnify the effects of the other factors that determined the smaller populations.

If aphid numbers decline is not under stress control, then how the stress in the host plant is synchronized with the aphid colony dynamics should also be considered. If the host plant experiences water stress when the aphid colony is already in an advanced phase of decline, as in experiment 2 , it is likely there will be little effect on aphid population dynamics.

All experiments described in this paper were carried out under intermittent stress conditions as defined by Huberty \& Denno (2004), but the three cultivars were each subjected to different stress conditions. In experiment 1 the stressed plants received only one third of the water supplied to the control; in experiment 2 the amount of water supplied to the plants that were water stressed was gradually reduced; in experiment 3 the stressed plants received the same amount of water as the control, but only if they wilted, that is, the watering interval was different. Our data showed that a pulsed water stress condition, by itself, does not necessarily result in a positive response in terms of the growth and development of $M$. euphorbiae feeding on tomato. This result is in accordance with that recently obtained for another aphid species. In fact, Simpson et al. (2012) studying the response of Myzus persicae to plant water stress imposed on Brassica oleracea var. capitata showed that the pulsed stress hypothesis does not account for the response of the aphid in this plant-pest system.

Previous studies on the same species of aphid report that the effect of water stress depends on host plant species (Kennedy et al., 1950; Kennedy \& Booth, 1959; 
Wearing \& van Emden, 1967). Few studies deal with the response of aphids to water stress in different cultivars of the same species of host plant (DeVries \& Manglitz, 1982; Dorschner et al., 1986). Previous results for different cultivars of alfalfa and wheat did not reveal any significant cultivar effects or interactions. In marked contrast we recorded a cultivar effect on the reproductive performance of aphids on tomato under water stress conditions. Numbers of aphids either increased or decreased depending on the cultivar and stress level. In the conditions experienced here, the effects, though significant, are not dramatic; nevertheless, in different conditions (i.e. a different plant phenological stage, larger initial infestation) we cannot exclude important implications for the integrated management of $M$. euphorbiae infesting tomato. This needs of course to be specifically tested.

ACKNOWLEDGEMENT. This work was supported by the Italian Ministry of Education, University and Scientific Research (MIUR).

\section{REFERENCES}

Aloni B. \& Pressman E. 1981: Stem pithiness in tomato plants: The effect of water stress and the role of abscisic acid. Physiol. Plantarum 51: 39-44.

BAUGH B.A. \& PHILLIPS S.A. 1991: Influence of population density and plant water potential on Russian wheat aphid (Homoptera: Aphididae) alate production. - Environ. Entomol. 20: 1344-1348.

BoEge K. \& Marquis R.J. 2005: Facing herbivory as you grow up: the ontogeny of resistance in plants. - Trends Ecol. Evol. 20: $441-448$.

Bonnemaison L. 1951: Contribution à l'étude des facteurs provoquant l'apparition des formes ailées et sexuées chez les Aphidinae. - Ann. Épiphyt. 2: 1-380.

Braithwaite B.M. \& BlaKe C.D. 1961: Tomato yellow top virus: Its distribution, characteristics and transmission by the aphid Macrosiphum euphorbiae (Thom.). — Aust. J. Agr. Res. 12: 1100-1107.

Brodbeck B.V. \& Strong D.R. 1987: Amino acid nutrition of herbivorous insects and stress to host plants. In Barbosa P. \& Schultz J.C. (eds): Insects Outbreaks. Academic Press, New York, pp. 347-364.

Chowfla S.C., Sharma P.K. \& ThaKur P.D. 1999: Virus infecting tomato and their management. In Verma L.R. \& Sharma R.C. (eds): Diseases of Horticultural Crops: Vegetables, Ornamentals and Mushrooms. Indus Publishing, New Delhi, pp. 158-183.

Cirousse C., Bournoville R. \& Bonnemain J.L. 1996: Water deficit-induced changes in concentrations in proline and some other amino acids in the phloem sap of alfalfa. - Plant Physiol. 11: 109-113.

COOPER W.R. \& GogGIN F.L. 2005: Effects of jasmonateinduced defenses in tomato on the potato aphid, Macrosiphum euphorbiae. - Entomol. Exp. Appl. 115: 107-115.

DeVries N.E.L. \& Manglitz G.R. 1982: Spotted alfalfa aphid (Therioaphis maculata (Buckton)) (Homoptera: Aphididae): Water stress, amino acid content, and plant resistance. $-J$. Kans. Entomol. Soc. 55: 57-64.

DiXON A.F.G. 1992: Constraints on the rate of parthenogenetic reproduction and pest status of aphids. - Invertebr. Reprod. Dev. 22: 159-163.
Dixon A.F.G. \& GLEN D.M. 1971: Morph determination in the bird cherry-oat aphid, Rhopalosiphum padi L. - Ann. Appl. Biol. 68: 11-21.

Dixon A.F.G., Horth S. \& Kindlann P. 1993: Migration in insects - cost and strategies. - J. Anim. Ecol. 6: 182-190.

Dorschner K.W., Johnson R.C., Eikenbary R.D. \& Ryan J.D. 1986: Insect-plant interactions: greenbugs (Homoptera: Aphididae) disrupt acclimation of winter wheat to drought stress. - Environ. Entomol. 15: 118-121.

Fereres A., Gutierrez C., Del Estal P. \& Castañera P. 1988: Impact of the English grain aphid, Sitobion avenae (F.) (Homoptera: Aphididae), on yield of wheat plants subjected to water deficits. - Environ. Entomol. 17: 596-602.

GERSHENZON J. 1984: Changes in the levels of plant secondary metabolites under water and nutrient stress. - Recent Adv. Phytochem. 18: 273-320.

GogGin F.L., Williamson V.M. \& Ullman D.E. 2001: Variability in the response of Macrosiphum euphorbiae and Myzus persicae (Hemiptera: Aphididae) to the tomato resistance gene Mi. - Environ. Entomol. 30: 101-106.

Horn D.J. 1976: Insect Biology. W.B. Saunders, Philadelphia, $439 \mathrm{pp}$.

Houser J.S., Guyton T.L. \& Lowry P.R. 1917: The pink and green aphid of potato. - Ohio Agric. Exp. Stn. Bull. 317: 60-88.

Hsiao T.C. 1973: Plant responses to water stress. - Annu. Rev. Plant Physiol. 24: 519-570.

Huberty A.F. \& Denno R.F. 2004: Plant water stress and its consequences for herbivorous insects: a new synthesis. Ecology 85: 1383-1398.

Inbar M., Doostdar H. \& MAYer R.T. 2001: Suitability of stressed and vigorous plants to various insect herbivores. Oikos 94: 228-235.

Kennedy J.S. \& Bоотн C.O. 1959: Responses of Aphis fabae Scop. To water shortage in host plants in the field. - Entomol. Exp. Appl. 2: 1-11.

Kennedy J.S., Iвbotson A. \& Boоth C.O. 1950: The distribution of aphid infestation in relation to leaf age. 1. Myzus persicae (Sulz.) and Aphis fabae Scop., on spindle trees and sugar beet plants. - Ann. Appl. Biol. 37: 651-679.

Kennedy J.S., Lamb K.P. \& Bоoth C.O. 1958: Responses of Aphis fabae Scop. to water shortage in host plants in pots. Entomol. Exp. Appl. 1: 274-291.

Larocca A., Fanti P., Molinaro A., Mattia M.F. \& Battaglia D. 2011: Aphid performance on Vicia faba and two southern Italy Phaseolus vulgaris landraces. - Bull. Insectol. 64: 101-106.

LARSSON S. 1989: Stressful times for the plant stress-insect performance hypothesis. — Oikos 56: 277-283.

Li H., Payne W.A., Michels G.J. \& Rush C.M. 2008: Reducing plant abiotic and biotic stress: Drought and attacks of greenbugs, corn leaf aphids and virus disease in dryland sorghum. - Environ. Exp. Bot. 63: 305-316.

Matthews E.G. \& Kitching R.L. 1984: Insect Ecology. University Queensland Press, St. Lucia, $211 \mathrm{pp}$.

Matthews R.W. \& Matthews J.R. 1978: Insect Behaviour. John Wiley \& Sons, New York, 507 pp.

MatTSON W.J. \& HAack R.A. 1987: The role of drought in outbreaks of plant-eating insects. - Bioscience 37: 110-118.

MCMurtry J.A. 1962: Resistance of alfalfa to spotted alfalfa aphid in relation to environmental factors. - Hilgardia 32: 501-539.

McVean R.I.K. \& Dixon A.F.G. 2001: The effect of plant drought-stress on populations of the pea aphid Acyrthosiphon pisum. - Ecol. Entomol. 26: 440-443. 
Miles P.W., Aspinall D. \& Rosenberg L. 1982: Performance of the cabbage aphid, Brevicoryne brassicae (L.), on waterstressed rape plants, in relation to changes in their chemical composition. - Aust. J. Zool. 30: 337-345.

MittLeR T.E. \& DAdD R.H. 1966: Food and wing determination in Myzus persicae (Homoptera: Aphididae). - Ann. Entomol. Soc. Am. 59: 1162-1166.

Müller C.B., Williams I.S. \& Hardie J. 2001: The role of nutrition, crowding, and interspecific interactions in the development of winged aphids. - Ecol. Entomol. 26: 330-340.

Pérez-Alfocea F., Estañ M.T., Caro M. \& Guerrier G. 2006 : Osmotic adjustment in Lycopersicon esculentum and L. pennellii under $\mathrm{NaCl}$ and polyethylene glycol 6000 iso-osmotic stresses. - Physiol. Plantarum 87: 493-498.

Perniola M., Rivelli A.R. \& Candido V. 1994: Yield response to water and stress indexes on tomato. - Acta Hort. 376 : 215-225.

Pons X. \& Tatchell G.M. 1995: Drought stress and cereal aphid performance. - Ann. Appl. Biol. 126: 19-31.

Powell G., Tosh C.R. \& Hardie J. 2006: Host plant selection by aphids: behavioral, evolutionary, and applied perspectives. Annu. Rev. Entomol. 51: 309-330.

Price P.W. 1991: The plant vigor hypothesis and herbivore attack. - Oikos 62: 244-251.

RAVEN J.A. 1983: Phytophages of xylem and phloem: A comparison of animal and plant sapfeeders. - Adv. Ecol. Res. 13: $135-234$.

Rivelli A.R., Toma I., Trotta V., Fanti P., De Maria S. \& Battaglia D. 2012: Combined effect of water stress and Macrosiphum euphorbiae infestation on plant growth in tomato. In Stoddard F. \& Makela P. (eds): Proceedings of the $12^{\text {th }}$ Congress of the European Society for Agronomy, Helsinki, Finland, 20-24 August 2012. University of Helsinki, pp. 334-335.

SAlAS M.L. \& CORCuera L.J. 1991: Effect of environment on gramine content in barley leaves and susceptibility to the aphid Schizaphis graminum. - Phytochemistry 30: $3237-3240$.

Scott J.W., Jones J.B. \& Somodi G.C. 1995: Screening tomato accessions for resistance to Xanthomonas campestris pv. vesicatoria, race T3. - Hort. Sci. 30: 579-581.

Scott J.W., Jones J.B. \& Somodi G.C. 2001: Inheritance of resistance in tomato to race $\mathrm{T} 3$ of the bacterial spot pathogen. - J. Am. Soc. Hortic. Sci. 126: 436-441.

Simpson K.L.S., JACKSON G.E. \& GRACE J. 2012: The response of aphids to plant water stress - the case of Myzus persicae and Brassica oleracea var. capitata. - Entomol. Exp. Appl. 142: 191-202.
Srinivasa Rao N.K., Bhatt R.M. \& Sadashiva A.T. 2001: Tolerance to water stress in tomato cultivars. - Photosynthetica 38: $465-467$.

Sumner L.C., Need J.T., McNew R.W., Dorschner K.W., EikENBARY R.D. \& Johnson R.C. 1983: Response of Schizaphis graminum (Homoptera: Aphididae) to drought-stressed wheat, using polyethylene glycol as a matricum. - Environ. Entomol. 12: 919-922.

Sumner L.C., Dorschner K.W., Ryan J.D., Eikenbary R.D., Johnson R.C. \& McNew R.W. 1986: Reproduction of Schizaphis graminum (Homoptera: Aphididae) on resistant and susceptible wheat genotypes during simulated drought stress induced with polyethylene glycol. - Environ. Entomol. 15: 756-762.

Systat 2007: Systat 12: Statistics II. Systat Software Inc., San Jose, CA.

Van Ieperen W., Volkov V.S. \& Van Meeteren U. 2003: Distribution of xylem hydraulic resistance in fruiting truss of tomato influenced by water stress. - J. Exp. Bot. 54: 317-324.

WAdLEY F.M. 1923: Factors affecting the proportion of alate and apterous forms of aphids. Ann. Entomol. Soc. Am. 16: 279-303.

WaLgenBaCh J.F. 1997: Effect of potato aphid (Homoptera: Aphididae) on yield, quality, and economics of stakedtomato production. - J. Econ. Entomol. 90: 996-1004.

WATt A.D. 1986: The performance of the pine beauty moth Panolis flammea on water-stressed lodgepole pine Pinus contorta plants, a laboratory experiment. - Oecologia 70: 578-579.

WEARING C.H. 1967: Studies on the relation of insect and host plant: II. Effects of water stress in host plants in the fecundity of Myzus persicae (Sulz.) and Brevicoryne brassicae (L.). Nature 213: 1052-1053.

WEARING C.H. 1972: Responses of Myzus persicae and Brevicoryne brassicae to leaf age and water stress in brussels sprouts grown in pots. - Entomol. Exp. Appl. 15: 61-80.

WEARING C.H. \& VAN EMDEN H.F. 1967: Effects of water stress in host plants on infestation by Aphis fabae Scop., Myzus persicae (Sulz) and Brevicoryne brassicae (L.). - Nature 213: 1051-1052.

White T.C.R. 1969: An index to measure weather-induced stress of trees associated with outbreaks of psyllids in Australia. - Ecology 50: 905-909.

White T.C.R. 1984: The abundance of invertebrate herbivores in relation to the availability of nitrogen in stressed food plants. - Oecologia 63: 90-105.

Received August 16, 2012; revised and accepted May 23, 2013 